\title{
Biologic modulation in renal regeneration
}

\section{Benedetta Mazzinghi, Paola Romagnani \& Elena Lazzeri}

To cite this article: Benedetta Mazzinghi, Paola Romagnani \& Elena Lazzeri (2016):

Biologic modulation in renal regeneration, Expert Opinion on Biological Therapy, DOI:

10.1080/14712598.2016.1219336

To link to this article: http://dx.doi.org/10.1080/14712598.2016.1219336

Accepted author version posted online: 04

Aug 2016.

Published online: 04 Aug 2016.

Submit your article to this journal $₫$

View related articles $\sqsubset$

View Crossmark data $\widetilde{ }$ 
Publisher: Taylor \& Francis

Journal: Expert Opinion on Biological Therapy

DOI: $10.1080 / 14712598.2016 .1219336$

\title{
Review:
}

\section{Biologic modulation in renal regeneration}

Benedetta Mazzinghi ${ }^{1}$, Paola Romagnani ${ }^{1,2,3}$, Elena Lazzeri ${ }^{3}$.

${ }^{1}$ Nephrology Unit and Meyer Children's University Hospital, ${ }^{2}$ Department of Clinical and Experimental Biomedical Sciences, University of Florence, Excellence Centre for Research, Transfer and High Education for the development of DE NOVO Therapies (DENOTHE), University of Florence, Florence, Italy.

Correspondence should be addressed to:

Elena Lazzeri PhD and Paola Romagnani MD Excellence Centre DENOTHE

University of Florence,

Viale Pieraccini 6

50139, Firenze, Italy

e-mail: elena.lazzeri@unifi.it;

paola.romagnani@unifi.it.

\begin{abstract}
Introduction: Chronic kidney disease (CKD) is recognized as a health care problem of increasing importance. Following the discovery of renal progenitors, the investigation of new therapeutic approaches to promote the kidney regenerative capacity has received increasing research attention.
\end{abstract}

Areas covered: The authors discuss the current knowledge of glomerular regeneration by renal progenitors and the modulation of their behavior through chemical and biological agents. The regenerative capacity of renal progenitors after injury must be regulated in order to prevent an 
inefficient or excessive response that could lead to a failed attempt to replace lost podocytes. In addition, they discuss the most relevant pathways involved in tubular repair and how these could be modulated in order to obtain renal regeneration rather than progression of a fibrotic maladaptive response.

Expert opinion: Further studies are needed to establish the existence of tubular progenitors and their role in driving the tubular response after injury. Modulation of the endogenous renal regenerative capacity is a new approach in the treatment of kidney diseases. Research efforts that concentrate on the potential regenerative capacity of the kidney can be advantageous when the experimental results are translated into clinical practice and may open the way to new therapeutic strategies for CKD.

Key words: chronic renal failure, AKI, progression, CKD, tubule, glomerulus

\section{Introduction}

Chronic kidney disease (CKD) is recognized as a health care problem of increasing importance and for this reason, in 2002, guidelines were developed by independent, international, multidisciplinary work groups with clinical and technical expertise to find a uniform definition and classification for CKD [1]. The introduction of these guidelines showed that CKD is far more frequent than previously appreciated, affecting $>10 \%$ of the world's population $[2,3]$. In addition, acute kidney injury (AKI) is a global public health concern impacting 13.3 million patients per year [4] that associates with high morbidity and about 1.7 million deaths per year. Patients affect by an AKI episode risk developing $\mathrm{CKD}$ and end-stage renal disease (ESRD), or exacerbate a pre-existing condition of CKD accelerating the progression to ESRD [5-6]. For these reasons, finding new therapies for kidney diseases is mandatory. The definition of the mammal kidney as an organ with 
limited capacity to regenerate, due to its intricate architecture and its rich diversity of cell types [78], has been recently called into question. Emerging evidence have shown that the kidney contains a population of renal progenitors that have the potential to regenerate different portions of the damage nephron [9] (See explanatory box). In this review, we describe and discuss some very recent and noteworthy results on the modulation of renal regeneration and we suggest how new discoveries can be applied in order to eventually develop new therapies.

\section{GLOMERULAR REGENERATION: EVIDENCE AND MECHANISMS}

The first clinical evidence of glomerular regeneration was described in a study by Fioretto et al. 18 years ago. They observed regression of renal disease with glomerular and tubular architecture remodeling in patients affected by diabetic nephropathy who underwent pancreas transplantation after 10 years of normoglycemia [10,11]. Further evidences showed the renoprotective effect of renin-angiotensin-aldosterone system inhibitors (RAAS-1), either angiotensin-converting-enzyme inhibitors (ACE-I) or angiotensin receptor blockers (ARB). Patients with a continued RAAS-I therapy exhibited a stabilization and even amelioration of kidney function, that could delay or prevent the need of renal replacement therapies [12-15]. In various animal models of chronic proteinuric nephropathies, including aging, the treatment with ACE-I, ARB or their combination, as well as other therapeutic interventions not only avoided progressive renal damage but also fostered regression of glomerulosclerosis [9, 15-19]. In addition, through 3D reconstruction of the glomeruli using serial kidney sections was demonstrated that regeneration of segmental sclerosis and remodeling of the glomerular architecture can occur unless the glomeruli are not affected by global sclerosis [15]. In agreement, a previous experimental study described a correlation between the extension of glomerusclerosis and kidney function decline on one side and the degree of podocyte depletion following renal damage on the other [19]. Different possible mechanisms have been provided to understand the effects of renoprotective therapies, including the extracellular matrix deposition in sclerotic lesions and the cell survival promotion of the glomerular capillary tuft and 
Bowman's capsule [20]. Accordingly, in a rat model of advanced nephropathy ACE-I treatment reduced mesangial cell proliferation, remodeled glomerular endothelial architecture, and increased glomerular podocyte number [20]. Because podocytes have limited capacity to divide and they cannot restore glomerular architecture through cell division, the existence of an intrarenal glomerular progenitor was mostly likely. In recent years, strong evidence has suggested that Renal Progenitors Cells (RPCs) may exist in humans, and represent a potential source for podocyte replacement through proliferation and differentiation [21-23]. At the urinary pole of the Bowman's capsule a subset of parietal epithelial cells (PEC) with features of RPCs were identified. These cells co-express two progenitor markers, CD133, a trans-membrane glycoprotein and marker of several types of adult stem cells and CD24, a surface molecule expressed by renal embryonic cells. Isolated RPCs were characterized by the expression of transcription factors characteristic of different types of stem cells, and the presence of functional properties characteristic of stem cells, that are selfrenewal, high clonogenic efficiency and multidifferentiation potential [22, 24-26]. In the adult kidney, RPCs are distributed in a hierarchical sequence within the Bowman's capsule from immature progenitor cells, located at the urinary pole, to cells committed to become podocytes at the vascular pole [25]. When injected into a mouse model of Focal Segmental Glomerulosclerosis (FSGS), human RPCs engrafted, replaceed lost podocytes and improved proteinuria, suggesting that RPCs can differentiate into podocytes and promote podocyte regeneration. Using an inducible transgenic mouse model where PEC were tagged Appel et al. showed that these cells can differentiate into podocytes during adolescence, acquiring their structural and phenotypic characteristics [27]. Nevertheless, following studies using lineage tracing methods produced different results, showing that parietal epithelial cells do not migrate onto the glomerular tuft to replenish podocytes in adult mice in physiologic conditions and in models of glomerular hypertrophy [28]. However, Wanner et al. using a diphtheria toxin-mediated acute podocyte loss model demonstrated the regenerative capacity of podocytes, observing that newly generated ones replaced 38\% of lost podocytes [29]. Recently, Eng DG et al. using an inducible transgenic mouse 
model affected with cytotoxic anti-podocyte antibody-induced FSGS provided a new further evidence that PEC were able to regenerate podocytes [30]. In this model PEC, which were permanently labeled after induction, migrated from Bowman's capsule to the glomerular tuft and acquired podocyte features to replace lost ones [30]. However, when podocyte loss is severe, regeneration does not occur while hyperplastic cellular lesions as those seen in crescentic glomerulonephritis or collapsing glomerulopathy were observed in association with the production of extracellular matrix proteins. In particular, it was demonstrated that most cells forming these lesions express the RPC markers CD24 and CD133 with or without co-expression of podocyte markers. These results suggested that the generation of these lesions might be the consequence of an abnormal proliferative and migratory response of RPCs at various stage of their differentiation condition toward podocytes that failed to replace the injured podocytes [31-35].

Very recently, Lasagni et al. proposed a definite explanation about these two conflicting behaviours of RPCs, suggesting that the regenerative response of RPCs to podocyte injury influences the outcome of CKD [36]. Using an inducible transgenic mouse model of FSGS where podocytes were labeled, they observed that, either the remission of disease associated with proteinuria reduction or the progression of disease associated with persistent proteinuria were explained by the amount of regenerated podocytes. New podocytes descended not from preexisting podocytes but from unknown podocyte progenitors. To establish the origin of new podocytes, they generated an inducible transgenic mouse model of FSGS for RPCs lineage tracing using the regulatory region of the transcription factor Pax2, a molecule that plays important roles in kidney development and is specifically co-expressed with CD133 in human RPCs. This mouse model allowed authors to trace single Pax2 labelled cells and their progeny, demonstrating definitely that lost podocytes were replaced from Pax2 labelled cells, suggesting that these cells exhibit a renal progenitor phenotype in mice. Of note, the replacement of podocytes from Pax2 labelled cells was observed mainly within glomeruli of mice with proteinuria remission. An average of about $30 \%$ of the lost podocytes were replaced by Pax2 labelled cells that acquired structural and phenotypic characteristic of fully 
differentiated podocytes. By contrast, the analysis of kidneys in mice with persistent proteinuria exhibited a higher percentage of glomeruli with sclerosis and no new podocytes were observed in comparison to mice with proteinuria remission. In these mice, the percentage of Pax $2+$ cell-derived podocytes was irrelevant suggesting that the progression or remission of glomerular disorder depends on the balance between an efficient and dysfunctional differentiation of Pax $2+$ RPCs in fully podocytes. This study provides a definite answer to the role of RPCs as the source for podocyte regeneration after injury [36].

Recently, Pippin et al. described another putative source of renal progenitor cells such as cells of renine lineage (CoRL) located in the juxtaglomerular compartment (JGC) [37]. The authors, by using four different transgenic mouse models of FSGS, traced the fate of renin expressing cells and observed that CoRL had regenerative capacity and were able to replace both glomerular epithelial cells, PEC and podocytes [37]. Other studies suggested that CoRL are pluripotent progenitors also for mesangial cells, vascular smooth muscle cells and pericytes [37, 38]. Taken together, these data suggest that CoRL may represent upstream mesenchymal progenitors that generate parietal epithelial cells that, in turn, regenerate podocytes (Table 1).

\subsection{Targets and pathways that regulate RPC regenerative capacity}

Growing evidence suggests that the regenerative capacity of RPCs after injury must be strictly regulated to prevent an inefficient or excessive response that can lead to failed attempt to replace lost podocyte [32]. Several studies are now starting to identify mechanisms that regulate RPC growth and differentiation (Figure 1, Table 1).

2.1.1. SDF-1/CXCR4: The chemokine Stromal cell-derived factor (SDF-1) or CXCL12 and its own receptor CXCR4 are important regulators of stem and progenitor systems all over the body [39]. Several evidence suggest that this pathway is also a critical mediator of RPC function within the kidney in homeostatic as well as inflammatory conditions [39]. An inflammatory environment is 
known to induce an increase of CXCR4 expression on progenitor cells in renal proliferative disorders. Moreover, macrophages may activate podocytes to produce the CXCR4 ligand, SDF-1, that mediates progenitor migration and proliferation leading to hyperplasia [40]. In vitro and in vivo studies demonstrated that the CXCL12 inhibition increased podocyte number and enhanced RPC differentiation toward the podocyte lineage, thus improving regeneration [40]. In addition, the dual antagonism of the chemokine ligand Monocyte Chemotactic Protein-1 (MCP-1) or CCL2 and CXCL12 showed synergistic effects preventing the glomerulosclerosis in diabetic nephropathy adding up the protective effect on CCL2-mediated glomerular leukocyte recruitment with that on CXCL12-mediated loss of podocytes [40]. These findings promote CXCL12 blockade as a novel strategy to prevent more efficiently crescentic lesions and glomerulosclerosis and to foster the regenerative capacity of RPCs (Figure 1).

2.1.2 Notch and Wnt/ק-catenin: The signaling pathways that are involved in the control of RPC growth and differentiation are only partially known; among them, the Notch and Wnt/ $\beta$-catenin pathways are well known. Notch signaling controls the balance between podocyte loss and renewal provided by RPCs and influences the outcome of glomerular injury in a mouse model of FSGS [41]. In vitro experiments demonstrated that Notch activation in RPCs promotes their entry into the Sphase of the cell cycle, on the contrary, down-regulation of Notch signaling is essential for RPC differentiation into podocytes. Accordingly, blocking the Notch signaling in the regenerative phases in a mouse model of Adriamycin nephropathy induced a worsening of proteinuria and glomerulosclerosis [41, 42]. Persistent Notch activation induced podocytes to override the G2/M checkpoint, resulting in death by mitotic catastrophe [41, 43]. Furthermore, in a transgenic mouse model of collapsing FSGS, the inhibition of Notch signaling reduced RPC hyperplasia but worsened podocyte loss and proteinuria [42]. Recent data obtained in mice demonstrated that the $\mathrm{Wnt} / \beta$-catenin pathway is essential for correct cell fate decision of PEC during the late stages of nephrogenesis [44]. Indeed, conditional $\beta$-catenin knockout mice displied abnormal kidneys and had reduced renal function. Their kidney appeared hypoplastic, most of the glomeruli had aberrant 
morphology with underdeveloped capillary tufts and well-differentiated podocytes replaced PEC in the Bowman's capsule [44] (Figure 1).

2.1.3 Glycogen synthase kinases 3- $\alpha$ and $-\boldsymbol{\beta}$ (GSK3s): In a recent study, Lasagni et al. identified the glycogen synthase kinases $3-\alpha$ and $-\beta$ (GSK3s) inhibitor BIO as a strong promoter of RPCs differentiation toward podocyte, both in vitro and in vivo [36]. In vitro treatment with BIO of human RPCs enhanced their differentiation towards podocytes up-regulating nephrin expression, in comparison to exposure only to the differentiating molecule retinoic acid (RA). In particular, the authors observed that the effect of this compound is to synchronize cells in G0/G1 phase of the cell cycle and enhance RA binding to its specific response elements. This evidence was further confirmed by in vivo experiments. In mouse model of FSGS performed in inducible transgenic mice, where podocytes were tagged, the administration of BIO induced proteinuria remission with increased number of newly generated podocytes. Moreover, to verify if the presence of new podocyte after the treatment of BIO was due to an increase of RPCs differentiation toward the podocyte lineage the mouse model of FSGS was also performed in inducible Pax 2 transgenic mice where RPCs were tagged. Accordingly, the BIO treatment enhanced the number of RPCs (Pax2+ cells) that acquired structural and phenotypic markers of fully differentiated podocytes as WT1 and Synaptopodin [36]. These observations demonstrate that the course of CKD can be shifted from progression to remission by acting pharmacologically on the RPCs response to injury (Figure 1).

2.1.4 Retinoic acid (RA): RA is a strong inducer of RPC differentiation toward the podocyte lineage in vitro [45]. It induces upregulation of podocyte-specific genes, like nephrin, by binding to RARE in the promoter and inducing transcription [26]. Interestingly, the RPC capacity to differentiate toward podocytes in vitro can be impaired by exposure to albumin, which binds RA with high affinity. In mouse model of FSGS, blocking the endogenous RA synthesis increased albuminuria, glomerular injury and mortality [45]. These data suggest that RA is essential for a correct differentiation of RPCs into podocyte and that the presence of even a small amount of 
albumin within the Bowman's space reduces RA bioavailability and can be detrimental for a suitable regenerative process to occur [45]. These results provide a biological rationale for the wellestablished renoprotective role of RAAS-I. The effects of these proteinuria-lowering drugs are directed on the RPCs and neutralizing the sequestering activity of albumin restored their regenerative response [45] (Figure 1).

2.1.5 Micro-RNAs: Strong evidence showed that micro-RNAs (miRNA), that are smatl noncoding RNA that regulate gene expression at the post-transcriptional level, play a key role in stem cell selfrenewal and differentiation. In particular, miR-1915 and miR-1225-5p are expressed in adult RPCs and have been identified as regulators of stemness and differentiation capacity through the tight modulation of CD133, Pax2 and TLR2 [46]. Moreover, the Oct4/miR145 balance is involved in stemness maintenance during hypoxia [47]. A reduction during the hypoxia of miR-145, constitutively expressed by CD133+ cells from papilla, mediated by the activation of Oct4, possibly permitted cell proliferation and maintenance of progenitor phenotype. On the contrary, an upregulation of miR-145, concomitantly with the Oct4 reduction, was observed during the differentiation allowing cell maturation and the proliferation to stop.

Other miRNA families are described as important players in modulating podocyte physiology and diseases pathogenesis. The miR-30 family protects podocytes from apoptosis and cytoskeletal injury by inhibiting Notch1 and p53 [48]. Moreover, in a mice model of FSGS miR-193a and miR206 over-expression led to a cascade of podocyte-destabilizing events, starting with the downregulation of WT1 and Synaptopodin inducing cell death $[49,50]$. In addition to these studies, in a mouse model of nephrotoxic nephritis an inhibition of miR-193a resulted in reduced crescent formation and decreased proteinuria [51]. Taken together, these results suggest that miR-193a functions as a master switch that regulates the expression of PEC and podocyte markers in glomerular epithelial cells.

\subsection{Drugs and biological mediators that modulate RPC regenerative capacity}


Several drugs were described that may potentially modulate RPC capacity to proliferate and differentiate into podocytes and may thus be used to enhance glomerular regeneration (Figure 1, Table 1).

2.2.1 Renin-angiotensin-aldosterone system (RAAS): Given the well-established renoprotective effects of RAAS-I, some studies were performed in order to clarify if their beneficial effects are attributable to an enhancement of RPC differentiation into podocytes. In a rat model of glomerular injury, a subset of parietal epithelial cells characterized by the expression of the marker Neural cell adhesion molecule (NCAM) in the Bowman's capsule was considered responsible for the regression of glomerular lesions [52]. Indeed, after the administration of ACE-I was observed a reduced proliferative response by NCAM+PEC and a reduced extension of glomerular hyperplastic lesions. These data demonstrated the occurrence of a normal glomerular architecture restoration that prevented the progression toward glomerulosclerosis [52]. One of the mechanisms through which ACE-I worked was the involvement of the cell cycle inibitor C/EBP $\delta$. Indeed, ACE-I treatment in vitro resulted in an up-regulation of C/EBP $\delta$ expression that limited PEC proliferation. Accordingly, the exposure of PEC to angiotensin II reduced the expression of C/EBP $\delta$ and induced their proliferation. Moreover, the Angiotensin (Ang) II receptor AT1 which expression is up regulated in the hyperplastic lesions seems to play a key role in the mechanisms responsible for RPC proliferation and migration [53]. These evidences suggested a pivotal contribution of Ang II/AT1 pathway in abnormal RPC behavior in proliferative diseases and added another explanation to the renoprotective effects of ARB treatment [53]. Indeed, in patients affected by crescentic glomerulonephritis who underwent to ACE-I therapy was observed a total remission of glomerular hyperplasia associated to a reduction of RPC proliferation and a reduceced expression of AT1 receptor [53].

Very recently, Lichtnekert et al. described a new effect after administration of RAAS-I that determined an increased podocyte number in the absence of podocyte proliferation by acting on CoRL [54]. Indeed, by using an inducibile transgenic mouse model of FSGS where CoRL were 
tagged, the author observed that the administration of RAAS-I increased the proliferation in JGC, the migration towards the glomerulus and enhanced the plasticity of CoRL toward three different glomerular cell lineages (podocytes, parietal epithelial cells and mesangial cells) [54] (Figure 1). In addition, a recent study documented for the first time an effect of RAAS-I on the regeneration of kidney vasculature. After the administration of both ACE-I and Ang II/AT1 antagonist to rat model of progressive glomerular injury was observed an higher increased glomerular capillary volume and length than in control animals at the same age [55].

2.2.2 Steroids: The therapeutic benefit of corticosteroids in the management of glomerular diseases is well known, although if a direct effect on specific cell types of the glomerulus has been only partially understood. A recent study demonstrated that daily prednisone administration to mice with experimental FSGS improves the outcomes increasing podocyte number and reducing proteinuria and glomerulosclerosis. Of note, this effect was due to the limit of podocyte apoptosis and to the enhancement of number of RPCs (Pax2+ cells) that acquired markers of podocytes as WT1 and Synaptopodin [56] (Figure 1).

2.2.3 Interferons: Interferons (INFs) were also reported as glomerular epithelial cells (RPC and podocyte) modulators in vitro and in vivo [57]. In vitro exposure of podocyte to either IFN- $\alpha$ or to IFN- $\beta$ demonstrated that only IFN- $\beta$ specifically alter the podocytes permeability and promote their loss by inducing mitotic catastrophe. On the contrary in vitro exposure of RPCs to either IFN- $\alpha$ or to IFN- $\beta$ demonstrated that only IFN- $\alpha$ affected proliferation and migration of RPCs. Moreover, in yitro exposure to both IFNs impaired the differentiation of RPCs into mature podocytes. This evidence was further confirmed by in vivo experiments. The injection either IFN- $\alpha$ or IFN- $\beta$ into mice with Adriamycin-induced nephropathy worsened the proteinuria and the glomerular injury. In particular, the INFs had distinct effects. The administration of IFN- $\beta$ mainly affected podocyte decreasing their numbers. Instead, the administration of IFN- $\alpha$ predominately affected PEC inducing their cell cycle arrest and impairing podocyte repair [57] (Figure 1). 
2.2.4 Retinoic acid (RA): In mouse model of FSGS, the exogenous administration of RA that neutralize sequestering activity of albumin, allowed the regenerative response of RPCs, determining an increase in podocyte number and the improvement of renal function [45]. The data also showed that RA restores a correct differentiation of RPCs into podocyte and avoids generation of hyperplastic glomerular lesions and of glomerulosclerosis [45] (Figure 1).

2.2.5 Leptin: A recent study described that the administration of leptin promotes disease regression resulting in near-complete reversal of both structural and functional parameters in an animal model of advanced diabetic nephropathy [17]. In addition, leptin replacement resulted in the restoration of the podocyte number/density and in the increase of WT-1 positive and proliferating PEC. These observations suggest that PEC may be a potential reservoir to re-establish lost podocytes and that an efficient differentiation of PEC into podocytes is essential for the regression of diabetic nephropathy that might be pharmacologically enhanced (Figure 1).

\section{TUBULAR REGENERATION: EVIDENCE AND MECHANISMS}

The kidney has a remarkable capacity for repair and regeneration, which is evidenced by apparently complete recovery of function despite a relevant nephron loss, occurred after AKI. The current pathophysiological concept explaining functional recovery from AKI is based on the high proliferative capacity of all tubular epithelial cells after injury via a process of dedifferentiation, cell division and redifferentiation to replace adjacent lost tubular cells [58, 59]. Indeed, a large body of evidence demonstrates that tubular regeneration is orchestrated within the tubule itself. Humphreys et al. used genetic fate mapping and transgenic mice to label tubular epithelial cells or tubular interstitium, concluding that regeneration by surviving epithelial cells was the predominant mechanism of repair after ischemic injury and thus, rulling out the implication of extra-tubular cells [60]. However, this extensive tubular regenerative capacity is in the last decade questioned because 
epidemiological studies document that even mild AKI episodes imply a substantial risk of subsequent CKD [61]. Indeed, if whatever surviving tubular epithelial cell would have such a high capacity to proliferate and replace lost tubular cells after injury, this would not explain the reason why CKD is so frequent after an episode of AKI. In this regard, a recent publication by Rinkevich et al. observed that adult damaged kidneys could undergo tubulogenesis through clonal expansion of a small subset of tubular cells [62]. In this study, by using an inducible transgenic mouse model, driven by the specific tubular marker Actin promoter and by using the Confetti reporter the authors performed a clonal analysis on ischemic kidneys by analyzing tubular epithelial cells at the single cell level and evaluating the effective cell division. This reporter enables the expression of one out of four fluorescent proteins in a stochastic manner, thus allowing the examination of the individual behaviour of multiple cells and to visualize clonal expansion of single cells that will appear as continuous clusters of cells of the same color. These results supported the hypothesis about the presence of tubular-committed progenitors as responsible of the repair of the injured tubuli. Consistently, other investigators suggested the existence of a specific tubular cell subpopulation scattered intra tubular cells in humans with high regenerative potential and resistance to death [6366]. Indeed, human tubular-committed progenitors, that are scattered within the proximal tubule, thin descending limb and thick ascending limb of Henle's loop, the distal convoluted tubule and the connecting segments, are characterized by expression of RPC markers (CD133+CD24+) [63-67] and by the expression of cytokeratin 7 and cytokeratin 19 in presence of low levels of tubular markers $[63,64]$. Several studies have evidenced that these cells exhibited a flask shape with no, or less pronounced brush border and a unique ultra-structural charcteristics such as a condensed chromatin in smaller and darker nuclei compared to the surrounding cells $[65,66]$. In addition, the expression of vimentin, claudin-1 and COL7A1 in the basal compartment of these cells confer an increased adherence to the basement membrane and an increased robustness; whereas a high BCL2 expression associated with very few mitochondria confer a higher resistance to death compared to other tubular cells $[65,66]$. Indeed, CD133+ tubular progenitors exhibited an increased resistance to 
death in vitro in comparison to other tubular cells following exposure to potentially nephrotoxic agents like hemoglobin [64]. This evidence was further corroborated by Hansson et al. who developed an ex vivo explant culture system where the vascular clamping of human kidneys undergoing nephrectomy was utilized to simulate acute tubular necrosis [66-]. Although this procedure produced massive tubular necrosis CD133+ tubular progenitors survived, providing further functional evidence that these cells were more resistant to insult than bulk epithelium. In addition, even if in healthy human kidney CD133+ tubular progenitors represent only the $2-6 \%$ of all tubular cells, owned to their survival capacity they become the dominant existing population immediately after injury, since adjacent differentiated tubular cells preferentially die [63, 64]. This enrichment may explain why CD133+ tubular progenitor markers increase immediately after injury and why the increased prevalence of such an undifferentiated population may be wrongly interpreted as the result of dedifferentiation. Taken altogether, these studies suggest that tubular cells are heterogenous and that at least two distinct tubular populations (differentiated tubular cells and tubular progenitors), exhibiting different sensitivity to injury, could exist in healthy adult kidneys. Further studies are needed to enhance our knowledge of tubular regenerative capacity after injury and to define the putative existence of tubular progenitors and establish their role in response to injury.

\subsection{Targets to promote tubular regeneration}

Regardless of determining the actual existence of a tubular progenitor, cellular and molecular mechanisms of tubular repair after AKI have been extensively investigated in a variety of experimental models in order to identify a number of candidate therapies for AKI. The major challenge consists in considering the clinical relevance of these models in human AKI and how such models might be improved to optimize translation into successful clinical trials. Both human and animal studies have shown that a variety of intrinsic repair processes is activated rapidly after 
kidney injury $[60,68]$ and that progression toward ESRD results directly or indirectly to maladaptive repair processes. Maladaptive repair occurs in the tubular, vascular, and interstitial compartments in response to AKI, predisposing to development of interstitial fibrosis. A reduction in capillary density after AKI may exacerbate renal hypoxia and thus, promote interstitial fibrosis $[69,70]$. Paracrine signals such as the expression of profibrotic factors (Trasforming Growth Factor- $\beta$, TGF- $\beta$, Connective Tissue Growth Factor-B, CTGFB and Platelet-Derived Growth Factor B, PDGFB) produced from the local environment (tubular epithelial cells and infiltrating cells) synergize to expand and maintain interstitial changes [68]. More importantly, it is widely accepted the key role of tubular cells in favouring a pro-fibrotic response. Indeed, tubular epithelial cells represent a further source of profibrotic factors when they fail to proliferate and growth arrest in G2/M phase of cell cycle [71]. Thus, the main mediators of maladaptive processes are currently considered as the main targets in order to halt progression of renal damage and to foster renal regeneration (Figure 2).

3.1.1 Hypoxia and oxidative stress mediators: Capillary rarefaction resulting in hypoxia [69, 70] and oxidative stress $[72,73]$ may play a major role in both developments of AKI and subsequent progression towards CKD. Cells are endowed with powerful defensive mechanisms against hypoxia and oxidative stress (hypoxia-inducible factor, HIF and nuclear factor erythroid 2-related factor 2, Nrf2), and these may be appropriate therapeutic targets. HIF activation before induction of AKI ameliorates the degree of kidney injury [74] and more importantly, pharmacologic HIF activation prevented the development of fibrosis after ischemia reperfusion injury (IRI) in mice, resulting in an improved tissue repair and in a suppression of inflammation [74]. The antifibrotic effect is not obseryed if HIF activation occurs after induction of AKI, which may actually exacerbate tissue injury if chronic hypoxia is already present [74]. These observations emphasize that there is a narrow therapeutic window of HIF activation. Similarly, exogenous vascular endothelial growth factor (VEGF) administered to preserve renal capillaries also has a therapeutic window only in the early postinjury period, whereas it fails to protect when administered several weeks after injury 
[75]. Pharmacologic Nrf2 activation and subsequent upregulation of antioxidative genes ameliorated experimental bilateral ischemic AKI in mice [76] and improved aristolocholic acidinduced AKI in mice [77]. Because persistent oxidant stress is a feature of AKI models leading to fibrosis, pharmacologic Nrf2 activation is theoretically a promising approach to attenuate AKL to CKD transition (Figure 2).

3.1.2 Inflammatory mediators: AKI is accompanied by an inflammatory sterile response that contributes to tubular cell damage [68]. Macrophages are key regulators of inflammation and fibrosis as also demonstrated in a prospective study where the analysis of biopsies from CKD patients has revealed that the number of macrophages in the interstitium correlated directly with glomerular scarring, interstitial fibrosis, atrophic tubules, reduced capillary density, and decreased renal survival. Macrophages are characterized by a remarkable plasticity in responding to extracellular cues reflecting a heterogeneous phenotype and function of these cells. Indeed, it is possible to assign a phenotype to the macrophage population associated with a harmful proinflammatory function (M1classically activated cells) or with a tissue reparative function (M2 alternatively activated cells) [78]. Genetic or pharmacologic inhibition of macrophage colonystimulating factor 1 signaling blocked macrophage/dendritic cell proliferation decreased M2 polarization and inhibited recovery [79]. These findings showed an important role for colonystimulating factor 1 mediated expansion and polarization of resident renal macrophage/dendritic cells in renal tubule epithelial regeneration and suggest that more myeloid cell-derived mediators that enhance epithelial healing should be investigated. In addition, the predominant trigger for the associated-AKI inflammatory response is tubular cell necrosis, because the release of intracellular molecules (damage-associated molecular patterns, DAMPs) from dying tubular cells elicit several strong immunostimulatory effects. These molecules can activate a set of pattern recognition receptors, such as Toll-like receptors (TLRs), on tubular epithelial cells as well as on the interstitial dendritic cells [80]. The subsequent innate immune response involves the transcription of numerous proinflammatory cytokines and chemokines, which initiate the influx of various immune cell 
subsets into the kidney, contributing to amplification of the inflammatory response and enhancing immune-mediated tubular cell death. M2 macrophages produce IL-10 and growth factors like TGF$\beta$ that have regulatory roles in tissue repair such as anti-inflammatory and profibrotic effects [80]. To this regard, a recent study documented for the first time a role of IL-22, which is a member of the IL-10 family of cytokines, demonstrating a remarkable regulatory effect in tissue repair through activation the proliferation of tubular epithelial cells [81]. In particular, authors demonstrated that TLR4 agonists released from necrotic tubular cells is a strong specific stimulus for IL-22 secretion from interstitial dendritic cells and macrophages. Consistently, TLR4 blockade during the early phase and during the healing phase suppressed IL-22 production and impaired kidney regeneration, demonstrating that this cytokine is a previously unknown mediator of tubular epithelial cell regeneration during AKI recovery phase and that renal mononuclear phagocytes can also orchestrate kidney regeneration beyond renal inflammation (Figure 2).

3.1.3 Hippo and Notch signaling pathways: With advances in developmental biology, many signalling pathways that coordinate cell proliferation, death and differentiation are discovered. One important pathway is the Hippo pathway characterized by a three-step kinase cascade composed of Mst1/2 (mammalian sterile 20-like kinase 1/2), Lats1/2 (large tumour suppressor 1/2) and YAP (Yesassociated protein). The latter is the Hippo pathway major downstream effector as revealed in studies about heart, liver and intestinal regeneration [82, 83]. A recent study demonstrated the key role of YAP in controlling proliferation and redifferentiation of renal tubular cells after acute IRI [84]. After strengthening of YAP signalling by using digitoxin as a specific agonist, promotion of renal tubular cell proliferation was documented, but a subsequent exacerbation of fibrosis followed the attempt to repair in the kidneys of IRI-induced AKI rat models. These experiments suggest that YAP might exhibit bidirectional functions in AKI: during repair, YAP mainly exerted beneficial effect on proliferation of the injured renal tubular epithelial cells, however, a constant activation of YAP exacerbated postinjury fibrosis and prevented the redifferentiation of dedifferentiated tubular cells. Consistently, others have demonstrated that YAP promote renal fibrotic process, activating 
TGF- $\beta$ signalling via retaining activated $\operatorname{Smad} 2 / 3$ in the nucleus [85]. In vivo treatment with verteporfin, a specific YAP inhibitor, identifies this molecule as a novel potent inhibitor of experimental fibrosis. Indeed, this treatment reduced renal interstitial YAP abundance together to a decreased nuclear Smad2/3 accumulation and a decreased expression of fibrotic markers in the kidney [85]. Inhibition of YAP signaling represents a novel tool that can interfere with the regulation of TGF- $\beta /$ Smad signaling and identifies a promising new antifibrotic treatment strategy to halt the progression of CKD.

The Notch signaling pathway is another highly conserved mechanism of intercellular communication influencing a wide variety of developmental processes of the kidney throughout embryogenesis and adulthood [86]. Besides these, activation of Notch pathway has been implicated in tissue repair in the adult kidney [86]. Indeed, kidneys after experimental AKI in mice showed increased expression of Notch receptors, specifically Notch1-3, of the Notch ligands (Jagged-1, Jagged-2, Delta-like-4) and of the Notch target genes (Hes-1, Hey2, HeyL, Sox9 and PDGFB). Consistent with this, activation of Notch pathway in tubular epithelial cells caused a rapid development of tubulointerstitial fibrosis [87]. Blockade of the Notch pathway, by using $\gamma$-secretase inhibitor starting at $24 \mathrm{~h}$ and at $1-2 \mathrm{hrs}$ before ischemia-reperfusion injury, involved less interstitial edema formation, a decreased expression of the Notch receptors (Notch3 and Notch1), its ligands (Delta-like-4 and Jagged-1) and PDGFB leading to a reduction of fibrosis with an amelioration of renal function. These data demonstrate that the severity of kidney injury can be ameliorated by blocking Notch activation through pharmacologic inhibition of Notch activation following AKI [88] (Figure 2).

3.1.4. Cell cycle control: Recent discoveries have enhanced our understanding about the role of tubular cell cycle control in AKI repair. Cell cycle analysis in vivo proved to be predictive tool for determining the progression of kidney injury to either tubular epithelial cell proliferation and repair or fibrosis. After the first 24 hours of ischemic injury, tubular cells undergo apoptotic and necrotic cell death. In response, many of the surviving, normally quiescient proximal tubule epithelial cells 
proliferate and enter the cell cycle in order to cover the denuded area [89]. This process appears to be driven by various cyclins and cyclin-dependent kinases (Cdks) $\mathrm{Cdk} 4 / 6$ and $\mathrm{Cdk} 2$ and fast synthesized checkpoint proteins such as p21 [89]. Also referred to as CDK-interacting protein 1 (CIP1), p21 binds to and antagonizes cyclin-CDK complexes, resulting in G1 phase cell cycle arrest. Previous studies suggest that expression of the Cdk inhibitor p21 ameliorates the injury [90] and that overexpression of $\mathrm{p} 21$ or the use of other $\mathrm{Cdk}$ inhibitors can protect against cisplatin and ischemic cell death [91]. The cell exerts cell cycle arrest as a protective mechanism to avoid cell division when it is potentially damaged during stress and injury [92]. Therefore, the modulation of a transient expression of $\mathrm{Cdk} 4 / 6$ or $\mathrm{Cdk} 2$ inhibitors represents a novel strategy to improve renal repair and could provide protection against early tubular cell death but still allows subsequent proliferation in order to repopulate injured tubules. Thus, temporary G1 cell cycle arrest should reduce kidney damage; however, in order for cells to divide and begin the process of repair, they must enter and exit each phase of the cell cycle on schedule [92]. If the cells exit a phase too soon, or stay in a phase too long, the normal repair and recovery processes can become maladaptive [93]. Indeed, after a DNA damage involvement, if the cells do not re-initiate the cell cycle and remain arrested in G1 or G2 phase, a fibrotic phenotype can be favored, contributing to a late decline of renal function and providing a hypothetic pathophysiological link between AKI and CKD [71, 93, 94]. The association of G2/M arrest and production of profibrogenic growth factors, such as TGF-b and CTGF, from the tubular cells provide strong evidence that tubular cells arrested in G2/M have a primary role in determining the fibrotic response [71, 94]. In these conditions, the percentage of cells that underwent G2/M arrest correlated with the development of fibrosis [71, 94] and consistently, pharmacologic intervention, which increased number of tubular cells arrested in G2/M phase after AKI, worsened kidney fibrosis. By contrast, interventions, which enhance the movement through G2/M phase of cell cycle, were associated with less fibrosis and an improvement of tissue integrity $[95,96]$. Thus, the damaged tubular epithelial cell can contribute to fibrosis process via paracrine mechanisms that are potentiated by a state of accelerated senescence characterized by 
$\mathrm{G} 2 / \mathrm{M}$ arrest and production of profibrotic factors that, in turn, acts to upregulate profibrotic cytokine production. The presence of DNA damage associated with severe injury, secondary to ischemia, aristolochic acid exposure or unilateral ureteral obstruction, is the main cause to force tubular epithelial cells toward G2/M arrest. Indeed, activation of the ATM/ATR pathways that is characterized for downstream $\mathrm{G} 2 / \mathrm{M}$ arrest and secretion of fibrotic factors has been observed in rodent models and in kidney diseases in humans [94]. Taken altogether, these considerations suggest that the true division potential of tubular cells after injury is unknown and may be considerably lower than what previously thought. Interestingly, old pathology studies based on evaluation of the occurrence of mitoses, as the only proof of effective cell division in injured tubular tissue, reported that tubular division was rare [97]. This limited regenerative potential may better explain the high incidence of CKD observed in patients with previous AKI episodes and suggest that the use of pharmacologic activators that push tubular epithelial cells in the progression of cell cycle is theoretically a promising approach to attenuate the AKI to CKD transition (Figure 2).

3.1.5 Epigenetic modifications: Histone modifications, DNA methylation, and cromosomal conformational changes that regulate gene expression can be activated after kidney injury. Of note, by using zebrafish embryo as a screening tool, it was identified a new histone deacetylase inhibitor (HDACi), PTBA, which expanded the pool of renal progenitor cells in a proliferation-dependent manner [98]. Following this, an esterified analog of PTBA, 4mPTB, was identified as a molecule with higher efficacy than the parent compound in inducing expansion of the renal progenitor cell pool in zebrafish embryo [95]. Consistently, it was demonstrated, for the first time, that m4PTB treatment accelerated recovery and reduced postinjury fibrosis after IR-induced AKI in mice [97].

This finding is associated with activation of transcriptional programs involved in promoting cell cycle progression, a reduction in $\mathrm{G} 2 / \mathrm{M}$ arrest, and an increase in the proportion of proliferating tubular epithelial cells in the G1 and S phases of the cell cycle. These results suggest that 4mPTB accelerates functional recovery after AKI by enhancing effective regenerative capacity of surviving 
tubular epithelial cells. In addition, since m4PTB improves recovery from AKI when administered 24 hours after IRI in mice, it could be a drug particularly attractive because of its efficiency when adminstered in patients a few days after the occurrence of the initial insult. The HDACi are already described as promising drugs to improve renal function reducing fibrosis in a variety of different rodent models of CKD [99, 100]. The underlying mechanism of this improvement is uncertain but several hypotheses are generated and discussed. It has been shown that epigenetic changes obtained with histone hyperacetylation induced by $\mathrm{m} 4 \mathrm{PTB}$ decreases fibrosis by reprogramming interstitial fibroblasts [101]. However, since renal tubular cells activate inflammatory programs that drive interstitial fibrosis and $\mathrm{G} 2 / \mathrm{M}$ arrest of these cells is the expression of a maladaptive repair mechanism that promotes postinjury fibrosis in models of severe AKI [71], we can speculate about the hypothetical efficacy of m4PTB in reducing postinjury fibrosis by driving renal tubular cells through the G2/M checkpoint. Thus, the beneficial effects of m4PTB are mediated by positive regulation of cell cycle-dependent processes involved in renal tubular cell regeneration rather than a reduction in cell injury (Figure 2).

\section{Conclusions}

Many advances have been made on the modulation of renal regeneration. In the glomerulus, it has been demonstrated that targeting the regenerative response of RPC, by using pharmacological approaches or targeting potential pathways, is able to shift from progression to remission the glomerular disease, In the tubule, regardless of whether that the existence of tubular progenitors and their role in the regenerative response is still to be clarified, cellular and molecular mechanisms of tubular repair have been extensively investigated in order to identify a number of potential pathways to be targeted. The main mediators of maladaptive processes are currently considered as the main targets in order to halt progression of tubular damage and to foster tubular regeneration. Promising results have demonstrated that fostering tubular proliferation capacity may represents the 
critical aspect in order to obtain a shift toward tubular regeneration instead of progression of a maladaptive response.

\section{Expert opinion}

Identification of RPCs in the adult kidney was a crucial step forward in regenerative medicine, demonstrating that regenerative capacity of the adult kidney also exists in mammals. Targeting these cells by using pharmacological approaches or targeting potential pathways that, indirectly, are able to accelerate the regenerative response may be a near-term application of regenerative approaches. Experimental data have recently clarified how podocyte replacement by RPCs occurs, demonstrating that it could be limited or completely abolished when albumin within the Bowman's space increases even slightly, as it happens in proteinuric disorders, sequestering RA, the key molecule for RPC differentiation toward the podocyte [45]. Accordingly, in the advanced phases of the disease, the endogenous regeneration of the podocytes operated by RPCs seems unable to correct and replace successfully a significant amount of lost podocyte, and RPCs rather chaotically proliferate and migrate, leading to lesion formation and subsequent sclerosis [, 45, 53]. This phenomenon is not ineluctable, as underlined by the occurrence of glomerular regeneration when protein lowering drugs such as ACEis are used, and can be even pharmacologically enhanced, turning failure into success $[9,20]$. Indeed, the enhancement of the repair process operated by RPCs toward regeneration could be obtained through the delivery of further drugs $[9,20,56]$ or targeting putative renoprotective pathways [40-42, 44, 57]. In a recent study, Lasagni et al. identified the glycogen synthase kinases $3-\alpha$ and $-\beta$ (GSK3s) inhibitor BIO as a strong promoter of RPC differentiation toward podocyte by promoting RA mediated effects [36]. More importantly, treatment with GSK3s inhibitor BIO induced proteinuria remission by enhancing RPC differentiation into podocytes in inducible transgenic mouse models of FSGS, demonstrating that the shift from progression to remission of kidney disease it is possible by modulating the regenerative response of RPCs is possible. However, future studies will likely identify further 
candidate signaling pathways implicated in RPC' maintenance, regulation and response after injury. On the other hand, regarding the regeneration of the tubular compartment, how much can the tubule regenerates and who performs regeneration after an episode of AKI is still a source of controversy. Further studies are necessary to increase our knowledge of the tubule regenerative capacity after injury, enabling us to define the putative existence of tubular progenitors and to establish their role in response to injury. In particular, it would be necessary to identify the mouse counterpart of human tubular progenitors in the adult mouse kidney by using a marker specifically expressed by that progenitor population. Unfortunately, a marker that specifically allows progenitors tagging in mouse adult kidneys remains unknown. Despite this, novel experimental strategies are needed to provide the effective regenerative potential of all tubular cells. In this regard, since some relevant pathways in the regenerative response after AKI have been identified in preclinical experimental models, it would be neccessary to investigate also their potential therapeutic activity. However, none of these has been confirmed in a successful phase III clinical trial. The difficulty to validate each target in specific animal models that consider comorbidities that would alter patient susceptibility, such as diabetes, aging, obesity, cancer, and CKD, is the reason why preclinical models are useful to identify regenerative mechanisms, but fail to translate these results into successfully human studies. In addition, ideally, an experimental model should demonstrate protective activity of therapy beyond 6 hours postinjury, because clinical AKI is not routinely identified until 1 or more days postinjury for the deficiency of appropriate predictive biomarkers to guide selection, timing, and monitoring of therapy in patients. Common functional markers such as serum creatinine and blood urea nitrogen are late or insensitive indicators of AKI and their measurement are even completely useless in differentiating AKI from CKD. In 2013, Sapphire study [102] reported the results of a prospective, observational, international investigation that identified two new predictive biomarkers: tissue inhibitor of metalloproteinase-2 (TIMP-2) and insulin-like growth factor-binding protein 7 (IGFBP7). These two novel urinary biomarkers seemed to be noteworthy because they exhibited a key role in kidney damage prediction. For this reason, 
they recently received FDA approval to assess risk of AKI and prediction of subsequent CKD development. IGFBP7 and TIMP-2 are G1 cell cycle inhibitors, and their increased levels in urines occur during the very early phases of cellular stress. Since development of CKD after AKI is associated with cell cycle arrest of tubular epithelial cells, which upregulates profibrotic cytokine production, promoting a maladaptive repair [94], activation and deactivation of cell cycle arrest at critical clinical time points for a patient may also prove to be targets of therapeutic intervention in the future. For this reason, detection of urine TIMP-2 and IGFBP7 could be quite useful to recognize the moment to start the treatment in order to avoid progression of the injury. Thus, fostering tubular proliferation capacity may represents the critical aspect in order to obtain a shift toward renal regeneration instead of progression of a maladaptive response.

In conclusion, efforts that concentrates on the potential regenerative capacity of the kidney will be advantageous when the experimental results are translated into clinical practice and they will open the way to new therapeutic strategies to halt the progression of CKD.

\section{Funding:}

This study was supported by the European Research Council under the Consolidator Grant RENOIR (ERC-2014-CoG, grant 648274)

\section{Declaration of Interest}

The authors have no relevant affiliations or financial involvement with any organization or entity with a financial interest in or financial conflict with the subject matter or materials discussed in the manuscript. This includes employment, consultancies, honoraria, stock ownership or options, expert testimony, grants or patents received or pending, or royalties. 


\section{Article highlights Box}

- Glomerular regeneration is mainly driven by Renal Progenitors Cells (RPCs).

- Cells of renine lineage (CoRL) were described as a putative source of parietal epithelial cells that, in turn, regenerate podocytes.

- Targeting of several potential pathways may accelerate the regenerative response of RPCs through the modulation of their differentiation and proliferation.

- Several drugs or biological mediators may potentially modulate RPC/capacity to proliferate and differentiate into podocytes and may thus be used to enhance glomerular regeneration.

- The existence of a hypothetical population of tubular progenitors has been described in human adult kidney. Further studies are needed to enhance our knowledge of tubular regenerative capacity and to establish the role of putative tubular progenitors in response to injury.

- Targeting of several potential pathways may accelerate the regenerative response of tubular epithelial cells through maladaptive response inhibition.

\section{Explanatory box}

\section{Kidney architecture:}

- The nephron is the basic structural and functional unit of the kidney; it is considerably similar across phyletic groups and it is generated in a highly conserved manner. In mammals, the number of nephrons is roughly proportional to the body mass.

- Each nephron, consist of a glomerulus, qthe filtering unit, which is connected through a neck to a tubule, specialized for reabsorption and secretion.

- The glomerulus is composed of a Bowman's capsule and a network (as a tuft) of capillaries.

- The Bowman's capsule is composed of parietal epithelial cells and renal progenitor cells. 
- The tubule is divided into a proximal tubule, Henle's loop (thin descending limb, thin ascending limb and thick ascending limb) and a distal tubule that connects to an excretion unit.

\section{Critical cells of the nephron for the renal regeneration:}

- The podocytes represent one of the three components of the glomerular filtration barrier together with the fenestrated endothelial cell and the glomerular basement membrane (GBM). These cells have limited capacity to divide and they cannot restore glomerular architecture through cell division. For this reason, the replacement of these cells by an intrarenal glomerular progenitor is critical.

- Tubular epithelial cells play a central role in renal physiology and are the cell types most sensitive to ischemic and nephrotoxic injury. The high regenerative capacity of these cells after kidney injury is in the last decade questioned because epidemiological studies document that even mild AKI episodes imply a substantial risk of CKD that progresses toward ESRD because of the occurrence of maladaptive repair processes. For this reason, a better knowledge of several potential pathways that may accelerate the regenerative response of tubular epithelial cells through maladaptive response inhibition is mandatory. 
Figure legend:

Figure 1: Pathways and drugs that regulate RPC differentiation and/or proliferation are potential therapeutic targets to enhance the glomerular regeneration. RPCs: renal progenitor cells; GSK3s: Glycogen synthase kinases $3-\alpha$ and $-\beta$; IFN: Interferon; RA: Retinoic acid; AngII/AT1: Angiotensin (Ang) II receptor type 1, AT1

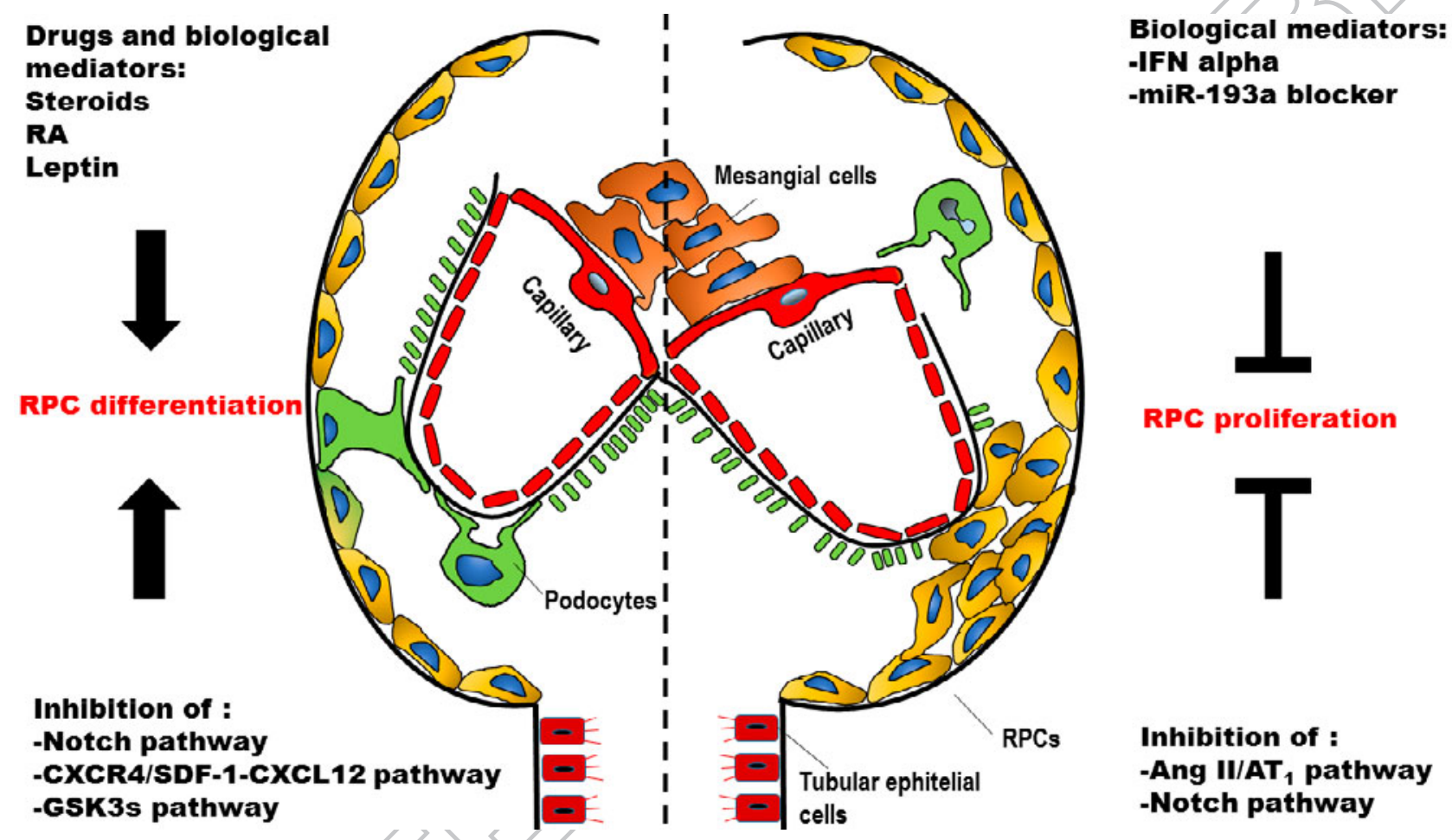


Figure 2: Pathways that are potential targets in order to promote tubular regeneration rather than progression of tubulointerstitial fibrosis. HIF: hypoxia-inducible factor; YAP: Yes-associated protein.

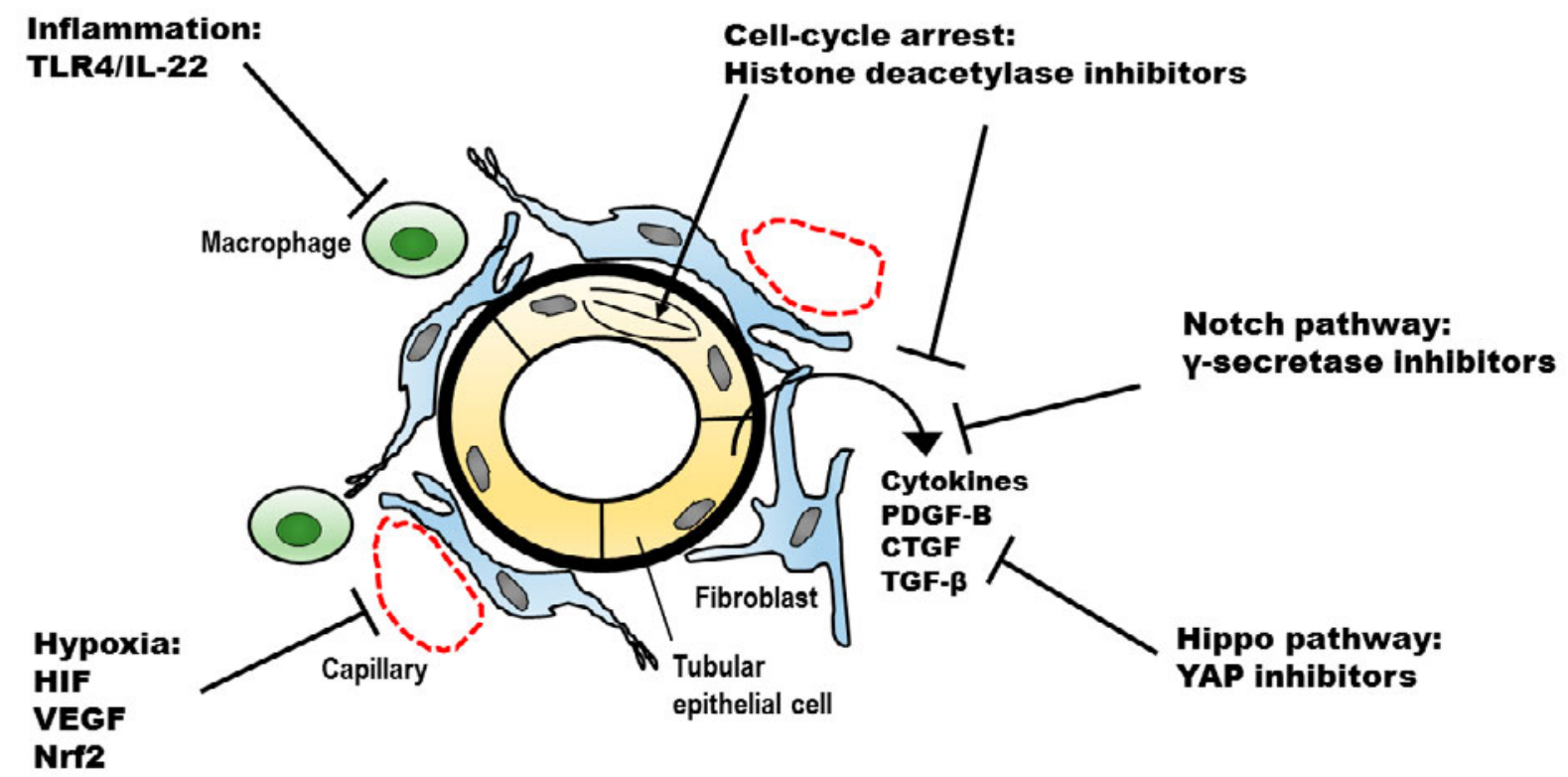


Table 1. Findings on glomerular regeneration.

ACE-I: agiotensin-converting-enzyme inhibitors; ARB: angiotensin receptor blockers, RAAS-I:

Renin-Angiotensin-Aldosterone System Inhibition; GSK3s: Glycogen synthase kinases 3- $\alpha$ and $-\beta$;

RPCs: renal progenitor cells; CoRL: cells of renine lineage; PEC: parietal epithelial cell; IFN:

Interferon.

\begin{tabular}{|c|c|c|c|c|}
\hline & DISEASE & TREATMENT & OBSER & REF \\
\hline \multirow{6}{*}{ 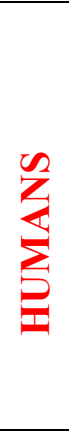 } & \multirow{2}{*}{\begin{tabular}{|l|}
\multicolumn{2}{|l|}{ Diabetic nephropathy } \\
$\begin{array}{l}\text { Chronic proteinuric } \\
\text { nephropathies }\end{array}$ \\
Chronic
\end{tabular}} & \multirow[t]{2}{*}{ Pancreas transplantation } & $\begin{array}{l}\text { Amelioration of renal function and regression of } \\
\text { glomerular and tubular lesions }\end{array}$ & 10 \\
\hline & & & $\begin{array}{l}\text { Amelioration of renal function and reduction of } \\
\text { proteinuria }\end{array}$ & 12 \\
\hline & $\begin{array}{l}\text { Chronic proteinuric } \\
\text { nephropathy }\end{array}$ & Multi-drug treatment & Stabilization & 14 \\
\hline & Diabetic nephropathy & Pancreas transplantation & Regression of tubulo-interstitial lesions & 11 \\
\hline & $\begin{array}{l}\text { Chronic proteinuric } \\
\text { nephropathy }\end{array}$ & Multi- & Stabilization of renal & 13 \\
\hline & $\begin{array}{l}\text { Proliferative } \\
\text { glomerulonephritis }\end{array}$ & $\begin{array}{l}\text { Angiotensin II type I } \\
\text { receptor blockers }\end{array}$ & Reduction of RPCs proliferation & 53 \\
\hline & Hypertension & $\mathrm{ARB}$ & $\begin{array}{l}\text { Normalization of renal function, normalization of } \\
\text { pathologic damage }\end{array}$ & 16 \\
\hline & 5/6 nephrectomy & $\mathrm{ACE}-$ & Regression of glomerulosclerosis & 18 \\
\hline & $\begin{array}{l}\text { Genetically-determined } \\
\text { progressive renal injury }\end{array}$ & $\mathrm{ACE}$ & $\begin{array}{l}\text { Reduction of glomerulosclerosis, increase in } \\
\text { capillary tissue, stabilization of interstitial injury }\end{array}$ & 15 \\
\hline & $\begin{array}{l}\text { Spontaneous glomerular } \\
\text { injury }\end{array}$ & & $\begin{array}{l}\text { Regression of functional and structural changes, } \\
\text { increase in the number of glomerular podocytes and } \\
\text { of parietal podocytes }\end{array}$ & 20 \\
\hline & Diabetic nephr & & $\begin{array}{l}\text { Reversal of both functional and structural measures } \\
\text { of advanced diabetic nephropathy. Increase in } \\
\text { podocyte number }\end{array}$ & 17 \\
\hline & Diabetic nephropathy & CXCL12 antagonist & Increase of podocyte number & 40 \\
\hline$U$ & $\begin{array}{l}\text { Focal segmental } \\
\text { glomerulosclerosis }\end{array}$ & Not & Differentiation of RPCs into podocytes & 41 \\
\hline 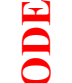 & $\begin{array}{l}\text { Collapsing focal segmental } \\
\text { glomerulosclerosis }\end{array}$ & Notch inhibition & $\begin{array}{l}\text { Decrease of parietal epithelial cell lesions, } \\
\text { worsening of proteinuria }\end{array}$ & 42 \\
\hline 2 & $\beta$-catenin-deficient mice & $\begin{array}{l}\text { Conditional } \beta \text {-catenin } \\
\text { knock out }\end{array}$ & $\begin{array}{l}\text { Switch in lineage differentiation of PECs toward a } \\
\text { podocyte-like cell fate }\end{array}$ & 44 \\
\hline 3 & $\begin{array}{l}\text { Focat segmental } \\
\text { glomerulosclerosis }\end{array}$ & GSK3s inhibitor & $\begin{array}{l}\text { Proteinuria remission with increased number of } \\
\text { newly generated podocytes. }\end{array}$ & 36 \\
\hline & Podocyte injury model & Exogenous miR-30 & Ameliorate proteinuria and podocyte injury & 48 \\
\hline & Nephrotoxic nephritis & miR-193a blocker & Reduce crescent formation, decrease proteinuria & 51 \\
\hline & Glomerular injury & ACE-I & Reduction of RPCs proliferation & 52 \\
\hline & $\begin{array}{l}\text { Crescentic } \\
\text { Glomerulonephritis }\end{array}$ & $\begin{array}{l}\text { Angiotensin II type I } \\
\text { receptor blockers }\end{array}$ & Reduction of RPCs proliferation & 53 \\
\hline & $\begin{array}{l}\text { Focal segmental } \\
\text { glomerulosclerosis }\end{array}$ & RAAS-I & Enhance the plasticity of CoRL & 54 \\
\hline & $\begin{array}{l}\text { Focal segmental } \\
\text { glomerulosclerosis }\end{array}$ & Prednisone & Increase of podocyte number & 56 \\
\hline & $\begin{array}{l}\text { Adriamycin-induced } \\
\text { nephropathy }\end{array}$ & IFN- $\beta$ & Suppression of PEC differentiation into podocyte & 57 \\
\hline & $\begin{array}{l}\text { Adriamycin-induced } \\
\text { nephropathy }\end{array}$ & IFN- $\alpha$ & Reduction of PEC proliferation & 57 \\
\hline & Focal segmental & Retinoic Acid & Increase of podocyte number, improve of renal & 45 \\
\hline
\end{tabular}




\section{Bibliography}

Papers of special note have been highlighted as either of interest $(\bullet)$ or of considerable interest (••) to readers.

1. National Kidney Foundation. K/DOQI clinical practice guidelines for chronic kidney disease: evaluation, classification, and stratification. Am J Kidney Dis 2002;39:S1-266

2. Levey AS, Coresh J. Chronic kidney disease. Lancet 2012;379:165-80

3. James MT, Hemmelgarn BR, Tonelli M. Early recognition and prevention of chronic kidney disease. Lancet 2010;375:1296-309

4 Mehta RL, Cerda J, Burdmann EA, et al. International Society of Nephrology's 0by25 initiative for acute kidney injury (zero preventable deaths by 2025): a human rights case for nephrology. Lancet 2015;385:1-28

5. Chawla LS, Eggers PW, Star RA, Kimmel PL.Acute kidney injury and chronic kidney disease as interconnected syndromes. N Engl J Med 2014;371:58-66.

6. Ishani A, Xue JL, Himmelfarb J, et al. Acute kidney injury increases risk of ESRD among elderly.

J/Am Soc Nephrol 2009;20:223-8

7. Little MH.Regrow or repair:potential regenerative therapies for the kidney. J Am Soc Nephrol $2006 ; 17: 2390-401$

8. Sagrinati C, Ronconi E, Lazzeri E, et al. Stem-cell approaches for kidney repair: choosing the right cells. Trends Mol Med 2008;14:277-85 
9. Benigni A, Morigi M, Remuzzi G. Kidney regeneration. Lancet 2010;375:1310-7

- This reviewsummararizes the recent literature on the evidence that the regeneration in the kidney can occur.

10. Fioretto P, Steffes MW, Sutherland DE, et al. Reversal of lesions of diabetic nephropathy after pancreas transplantation. N Engl J Med 1998;339:69-75

- This article show the first clinical evidence of glomerular regeneration.

11. Fioretto P, Sutherland DE, Najafian B, Mauer M. Remodeling of renal interstitial and tubular lesions in pancreas transplant recipients. Kidney Int 2006;69:907-12

12. Ruggenenti P, Perna A, Benini R, et al. In chronic nephropathies prolonged ACE inhibition can induce remission: dynamics of time-dependent changes in GFR. Investigators of the GISEN Group. Gruppo Italiano Studi Epidemiologici in Nefrologia. J Am Soc Nephrol 1999;10:997-1006

13. Ruggenenti P, Perticucci E, Cravedi P, et al. Role of remission clinics in the longitudinal treatment of CKD. J Am Soc Nephrol 2008;19:1213-24

- The results of a multimodal intervention to target urinary proteins in 56 consecutive patients are reported.

14. Ruggenenti $\mathrm{P}$, Brenner BM, Remuzzi G. Remission achieved in chronic nephropathy by a multidrug approach targeted at urinary protein excretion. Nephron 2001;88:254-9

15. Remuzzi A, Gagliardini E, Sangalli F, et al. ACE inhibition reduces glomerulosclerosis and regenerates glomerular tissue in a model of progressive renal disease. Kidney Int 2006;69:1124-30

16. Boffa JJ, Lu Y, Placier S, et al. Chatziantoniou C. Regression of renal vascular and glomerular fibrosis: role of angiotensin II receptor antagonism and matrix metalloproteinases. J Am Soc Nephrol 2004;14:1132-44 
17. Pichaiwong W, Hudkins KL, Wietecha T, et al. Reversibility of structural and functional damage in a model of advanced diabetic nephropathy. J Am Soc Nephrol 2013;24:1088-102

18. Ma LJ, Nakamura S, Aldigier JC, et al. Regression of glomerulosclerosis with high-dose angiotensin inhibition is linked to decreased plasminogen activator inhibitor-1. J Am Soc Nephrol 2005;16:966-76

19. Wiggins RC. The spectrum of podocytopathies: A unifying view of glomerular diseases. Kidney Int 2007;71:1205-14

20. Macconi D, Sangalli F, Bonomelli M, et al. Podocyte repopulation contributes to regression of glomerular injury induced by ACE inhibition. Am J Pathol 2009;174:797-807

21. Romagnani P. Toward the identification of a "renopoietic system"? Stem Cells 2009;27:2247-53

22. Romagnani P, Lasagni L, Remuzzi G. Renal progenitors: an evolutionary conserved strategy for kidney regeneration. Nat Rev Nephrol 2013;9:137-46

23. Shankland SJ, Smeets B, Pippin JW, Moeller MJ. The emergence of the glomerular parietal epithelial cell. Nat Rev Nephrol 2014,10:158-73

24. Angelotti ML, Ronconi E, Ballerini L, et al. Characterization of renal progenitors committed toward tubular lineage and their regenerative potential in renal tubular injury. Stem Cells $2012 ; 30: 1714-25$

25. Sagrinati C, Netti GS, Mazzinghi B, et al. Isolation and characterization of multipotent progenitor cells from the Bowman's capsule of adult human kidneys. J Am Soc Nephrol 2006; 17 : 2443-56.

- The identification and characterization of renal progenitor cells in adult human kidneys. The ability of these cells to repair renal damage suggest their potential in the treatment of 


\section{renal failure.}

26. Ronconi E, Sagrinati C, Angelotti ML, et al. Regeneration of glomerular podocytes by human renal progenitors. J Am Soc Nephrol 2009;20:322-32

27. Appel D, Kershaw DB, Smeets B, et al. Recruitment of podocytes from glomerular parietal epithelial cells. J Am Soc Nephrol 2009;20:333-43

28. Berger K, Schulte K, Boor P, et al. The regenerative potential of parietal epithelial cells in adult mice. J Am Soc Nephrol 2014;25:693-705

29. Wanner N, Hartleben B, Herbach N, et al. Unraveling the role of podocyte turnover in glomerular aging and injury. J Am Soc Nephrol 2014;25:707-16

30. Eng DG, Sunseri MW, Kaverina NV, et al. Glomerular parietal epithelial cells contribute to adult podocyte regeneration in experimental focal segmental glomerulosclerosis. Kidney Int 2015;88:999-1012

31. Romagnani P, Remuzzi G. Renal progenitors in non-diabetic and diabetic nephropathies. Trends Endocrinol Metab 2013;24:13-20

32. Lasagni L, Romagnani P. Glomerular epithelial stem cells: the good, the bad, and the ugly. J Am Soc Nephrol 2010;21:1612-9

33. Smeets B, Uhlig S, Fuss A, et al. Tracing the origin of glomerular extracapillary lesions from parietal epithelial cells. J Am Soc Nephrol 2009;20:2604-15

34. Smeets B, Kuppe C, Sicking EM, et al. Parietal epithelial cells participate in the formation of sclerotic lesions in focal segmental glomerulosclerosis. J Am Soc Nephrol 2011;22:1262-74

35. Smeets B, Angelotti ML, Rizzo P, et al. Renal progenitor cells contribute to hyperplastic glomerular lesions of different types of podocytopathies and in crescentic glomerulonephritis. J Am 
Soc Nephrol 2009;20:2593-603

36. Lasagni L, Angelotti ML, Ronconi E, et al. Podocyte regeneration driven by renal progenitors determines glomerular disease remission and can be pharmacologically enhanced. Stem Cell Reports 2015;5:248-63

-. This study demonstrates that the regenerative response of RPCs to podocyte injury influences the outcome of CKD.

37. Pippin JW, Sparks MA, Glenn ST, et la. Cells of renin lineage are progenitors of podocytes and parietal epithelial cells in experimental glomerular disease. Am J Pathol 2013;183:542-57

38. Starke C, Betz H, Hickmann L,et al Renin lineage cells repopulate the glomerular mesangium after injury. J Am Soc Nephrol 2015;26:48-54

39 Anders HJ, Romagnani P, Mantovani A.Pathomechanisms: homeostatic chemokines in health, tissue regeneration, and progressive diseases. Trends Mol Med 2014;20:154-65

40. Darisipudi MN, Kulkarni OP, Sayyed SG, et al. Dual blockade of the homeostatic chemokine CXCL12 and the proinflammatory chemokine CCL2 has additive protective effects on diabetic kidney disease. Am J Pathol 2011;179:116-24

41. Lasagni L, Ballerini L, Angelotti ML, et al. Notch activation differentially regulates renal progenitors proliferation and differentiation toward the podocyte lineage in glomerular disorders. Stem Cells 2010;28:1674-85

42. Ueno T, Kobayashi N, Nakayama M, et al. Aberrant Notch1-dependent effects on glomerular parietal epithelial cells promotes collapsing focal segmental glomerulosclerosis with progressive podocyte loss. Kidney Int 2013;83:1065-75

43. Lasagni L, Lazzeri E, Shankland SJ, et al. Podocyte mitosis - a catastrophe. Curr Mol Med 
2013;13:13-23.

44. Grouls S, Iglesias DM, Wentzensen N, et al. Lineage specification of parietal epithelial cells requires $\beta$-catenin/Wnt signaling. J Am Soc Nephrol 2012;23:63-72.

45. Peired A, Angelotti ML, Ronconi E, et al. Proteinuria impairs podocyte regeneration by sequestering retinoic acid. J Am Soc Nephrol 2013;24:1756-68

46 Sallustio F, Serino G, Costantino V, et al. miR-1915 and miR-1225-5p regulate the expression of CD133, PAX2 and TLR2 in adult renal progenitor cells. PLoS One 2013;8:e68296

47 Bussolati B, Moggio A, Collino F, et al. Hypoxia modulates the undifferentiated phenotype of human renal inner medullary CD133+ progenitors through Oct4/miR-145 balance. Am J Physiol Renal Physiol 2012;302:F116-28

$48 \mathrm{Wu}$ J, Zheng C, Fan Y, et al. Downregulation of microRNA-30 facilitates podocyte injury and is prevented by glucocorticoids. J Am Soc Nephrol 2014;25:92-104

49 Gebeshuber CA, Kornauth C, Dong L, et al. Focal segmental glomerulosclerosis is induced by microRNA-193a and its downregulation of WT1. Nat Med.2013;19:481-7

50 Guo N, Guo J, Su D. MicroRNA-206 and its down-regulation of Wilms'Tumor-1 dictate podocyte healthin adriamycin-induced nephropathy. Ren Fail 2016 [Epub ahead of print]

51 Kietzmann L, Guhr SS, Meyer TN, et al. MicroRNA-193a Regulates the Transdifferentiation of Human Parietal Epithelial Cells toward a Podocyte Phenotype. J Am Soc Nephrol 2015;26:1389401

52. Benigni A, Morigi M, Rizzo P, et al. Inhibiting angiotensin-converting enzyme promotes renal repair by limiting progenitor cell proliferation and restoring the glomerular architecture. Am J Pathol 2011;179:628-38 
53. Rizzo P, Perico N, Gagliardini E, et al. Nature and mediators of parietal epithelial cell activation in glomerulonephritides of human and rat. Am J Pathol 2013;183:1769-78

\section{- This study demonstrates the role of ACE inhibitors in podocyte repopulation, contributing to regression of glomerular injury through a reduction of RPC proliferation.}

54. J Lichtnekert J, Kaverina NV, Eng DG et al. Renin-Angiotensin-Aldosterone System Inhibition Increases Podocyte Derivation from Cells of Renin Lineage, J.Am Soc Nephrol 2016; Epub ahead of print]

55 Remuzzi A, Sangalli F, Macconi D, et al. Regression of Renal Disease by Angiotensin II Antagonism Is Caused by Regeneration of Kidney Vasculature. J Am Soc Nephrol 2016; 27:699705

56. Zhang J, Pippin JW, Krofft RD, et al. Podocyte repopulation by renal progenitor cells following glucocorticoids treatment in experimental FSGS. Am J Physiol Renal Physiol 2013;304:F1375-89

57. Migliorini A, Angelotti ML, Mulay SR, et al. The antiviral cytokines IFN- $\alpha$ and IFN- $\beta$ modulate parietal epithelial cells and promote podocyte loss: implications for IFN toxicity, viral glomerulonephritis, and glomerular regeneration. Am J Pathol 2013;183:431-40

58. Sharfuddin AA, Molitoris BA. Pathophysiology of ischemic acute kidney injury. Nat Rev Nephrol 201 1;7:189-200

59. Zuk A, Bonventre JV. Acute Kidney Injury. Annu Rev Med 2016;67:293-307

60. Humphreys BD, Valerius MT, Kobayashi A, et al: Intrinsic epithelial cells repair the kidney after injury. Cell Stem Cell 2008;2:284-91

61. Bellomo R, Kellum JA, Ronco C. Acute kidney injury. Lancet 2012;380:756-66

62. Rinkevich Y, Montoro DT, Contreras-Trujillo H et al. In vivo clonal analysisreveals lineage- 
restricted progenitor characteristics in mammalian kidney development, maintenance, and regeneration. Cell Rep 2014;7:1270-83

- This study demonstrates that adult damaged kidneys undergo tubulogenesis through clonal expansion of a small subset of tubular cells, suggesting the existence of tubular-committed progenitors as responsible of the repair.

63. Lindgren D, Boström A-K, Nilsson K,et al. Isolation and characterization of progenitor-like cells from human renal proximal tubules. Am J Pathol 2011;178:828-37

64. Angelotti ML, Ronconi E, Ballerini L, et al. Characterization of renal progenitors committed toward tubular lineage and their regenerative potential in renal tubular injury. Stem Cells 2012;30:1714-25

- This study demonstrates the existence of tubular-committed progenitors with an increased resistance to death in comparison to other tubular cells.

65. Smeets B, Boor P, Dijkman H,et al: Proximal tubular cells contain a phenotypically distinct, scatteredcell population involved in tubular regeneration. J Pathol 2013;229: 645-59

66. Hansson J, Hultenby K, Cramnert C, et al. Evidence for a morphologically distinct and functionally robust cell type in the proximal tubules of human kidney. Hum Pathol 2014; 45: 38293

67 Bussolati B, Moggio A, Collino F, et al. Hypoxia modulates the undifferentiated phenotype of human renal inner medullary CD133+ progenitors through Oct4/miR-145 balance. Am J Physiol Renal Physiol 2012, 302:F116-28

68. Bonventre JV, Yang L: Cellular pathophysiology of ischemic acute kidney injury. J Clin Invest $2011 ; 121: 4210-21$ 
69. Basile DP: The endothelial cell in ischemic acute kidney injury: Implications for acute and chronic function. Kidney Int 2007;72:151-6

70. Kramann R, Tanaka M, Humphreys BD: Fluorescence microangiography for quantitative assessment of peritubular capillarychanges after AKI in mice. J Am Soc Nephrol 2014;25:1924-31

71. Yang L, Besschetnova TY, Brooks CR, et al. Epithelial cell cycle arrest in G2/M mediates kidney fibrosis after injury. Nat Med 2010;16:535-43

-• This study demonstrates the association of G2/M arrest and production of profibrogenic growth factors from the tubular cells provide strong evidence that tubular cells arrested in G2/M have a primary role in determining the fibrotic response.

72. Kim J, Seok YM, Jung K-J, Park KM: Reactive oxygen species/oxidative stress contributes to progression of kidney fibrosis following transient ischemic injury in mice. Am J Physiol Renal Physiol 2009;297:F461-70

73. Basile DP, Leonard EC, Beal AG,et al. Persistent oxidative stress following renal ischemiareperfusion injury increases ANG II hemodynamic and fibrotic activity. Am J Physiol Renal Physiol 2012;302:F1494-502,

74. Kapitsinou PP, Jaffe J, Michael M, et al: Preischemic targeting of HIF prolyl hydroxylation inhibits fibrosis associated with acute kidney injury.AmJ Physiol Renal Physiol 2012;302:F117279

75. Leonard EC, Friedrich JL, Basile DP: VEGF-121 preserves renal microvessel structureand ameliorates secondary renal disease following acute kidney injury. Am J Physiol Renal Physiol 2008;295:F1648-57

76. Liu M, Reddy NM, Higbee EM, et al. The Nrf2 triterpenoid activator, CDDO-imidazolide, 
protects kidneys from ischemia-reperfusion injury in mice. Kidney Int 2014;85:134-41

77. Wu J, Liu X, Fan J, et al::Bardoxolone methyl (BARD) ameliorates aristolochic acid (AA)induced acute kidney injury through Nrf2 pathway. Toxicology 2014;318:22-31

78. Lee S, Huen S, Nishio H, et al.Distinct macrophage phenotypes contribute to kidney injury and repair. J Am Soc Nephrol 2011;22:317-26

79. Zhang M-Z, Yao B, Yang S, et al. CSF-1 signaling mediates recovery fromacute kidney injury. J Clin Invest 2012;122:4519-32

80 Anders H-J, Schaefer L: Beyond tissue injury damage-associated molecular patterns, toll like receptors, and inflammasomes also drive regeneration and fibrosis. J Am Soc Nephrol 2014;25:1387-400

81. Kulkarni OP, Hartter I, Mulay SR, et al. Toll-like receptor 4-induced IL-22 accelerates kidney regeneration. J AmSoc Nephrol 2014;25:978-89

82. Barry ER, Morikawa T, Butler BL, et al. Restriction of intestinal stem cell expansion and the regenerative response by YAP. Nature 2013;493:106-10

83. Grijalva JL, Huizenga M, Mueller K, et al. Dynamic alterations in Hippo signaling pathway and YAP activation during liver regeneration. Am. J. Physiol. Gastrointest. Liver Physiol 2014;307:G196-G204

84. Xu J, Li PX, Wu J, et al. Involvement of the Hippo pathway in regeneration and fibrogenesis after ischaemic acute kidney injury: YAP is the key effector. Clin Sci 2016;130:349-63

85. Szeto SG, Narimatsu M, Lu M, et al. YAP/TAZ Are Mechanoregulators of TGF- $\beta$-Smad Signaling and Renal Fibrogenesis. J Am Soc Nephrol; 2016 [Epub ahead of print]

86. Sirin Y, Susztak K. Notch in the kidney: development and disease. J Pathol. 2012;226:394-403 
87. Bielesz B, Sirin Y, Si H, et al. Epithelial Notch signaling regulates interstitial fibrosis development in the kidneys of mice and humans.J Clin Invest 2010;120:4040-54

88. Kramer J, Schwanbeck R, Pagel H, et al. Inhibition of Notch Signaling Ameliorates Acute Kidney Failure and Downregulates Platelet-Derived Growth Factor Receptor $\beta$ in the Mouse Model. Cells Tissues Organs 2016;201:109-17

89. Price PM, Safirstein RL, Megyesi J: The cell cycle and acute kidney injury. Kidney Int 2009;76: $604-13$

90. Megyesi J, Safirstein RL, Price PM: Inductionof p21WAF1/CIP1/SDI1/in kidney tubule cells affects the course of cisplatin-induced acute renal failure. J Clin Invest 1998;101:777-82

91. Di Rocco DP, Bisi J, Roberts P,et al: CDK4/6 inhibition induces epithelial cell cycle arrest and ameliorates acute kidney injury Am J Physiol Renal Physiol 2014;306:F379- 88

92. Kellum JA, Chawla LS. Cell-cycle arrest and acute kidney injury: the light and the dark sides. Nephrol Dial Transplant. 2016 Jan;31(1):16-22.

93. Chawla LS, Kimmel PL. Acute kidney injury and chronic kidney disease: an integrated clinical syndrome. Kidney Int 2012;82:516-249

94. Lovisa S, LeBleu VS, Tampe B, et al. Epithelial-to-mesenchymal transition induces cell-cycle arrest and parenchymal damage in renal fibrosis. Nat. Med 2015;21: 998-1009

This study provides strong evidence that tubular cells arrested G2/M have a primary role in determining the fibrotic response and that the percentage of cells that underwent $\mathrm{G} 2 / \mathrm{M}$ arrest correlate with the development of fibrosis.

95. Cianciolo Cosentino C, Skrypnyk NI, Brilli LL et al. Histone deacetylase inhibitor enhances recovery after AKI. J Am Soc Nephrol 2013;24:943-53 
96. Tang J, Liu N, Tolbert E et al. Sustained activation of EGFR triggers renal fibrogenesis after acute kidney injury. Am J Pathol 2013;183:160-72

97 Cuppage FE, Tate A. Repair of the nephron following injury with mercuric chloride. Am J Pathol 1967;51:405-29

98. de Groh ED, Swanhart LM, Cosentino CC, Jackson RL, Dai W, Kitchens CA, Day BW, Smithgall TE, Hukriede NA. Inhibition of histone deacetylase expands the renal progenitor cell population. J Am Soc Nephrol 2010;21:794-802

99. Van Beneden K, Geers C, Pauwels M,et al. Valproic acid attenuates proteinuria and kidney injury. J Am Soc Nephrol 2011;22:1863-75

100. Advani A, Huang Q, Thai K, et al. Long-term administration of the histone deacetylase inhibitor vorinostat attenuates renal injury in experimental diabetes through an endothelial nitric oxide synthase dependent mechanism. Am J Pathol 2011;178:2205-14

101. Pang M, Ma L, Liu N, et al. Histone deacetylase $1 / 2$ mediates proliferation of renal interstitial fibroblasts and expression of cell cycle proteins. J Cell Biochem 2011; 112: 2138-48

102. Kashani K, Al-Khafaji A, Ardiles $\mathrm{T}$ et al. Discovery and validation of cell cycle arrest biomarkers in human acute kidney injury. Crit Care 2013;17: R25. 